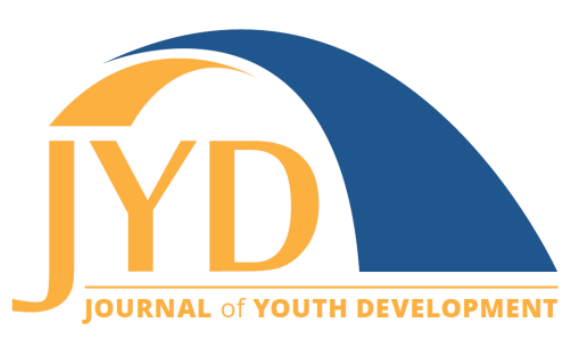

http://jyd. pitt. edu/ | Vol. 13 Issue 3 DOI 10.5195/jyd.2018.599 | ISSN 2325-4017 (online)

\title{
Online Child's Health Assessment Tool for Obesity Prevention Programming
}

\author{
Laura A. Palmer \\ Purdue University \\ Ipalmer@purdue.edu \\ Kimberly J. McCarthy \\ The Pennsy/vania State University \\ kxc255@psu.edu \\ Daniel F. Perkins \\ The Pennsy/vania State University \\ dfp102@psu.edu
}

Lynne M. Borden

University of Minnesota

Imborden@umn.edu

\section{Jennifer M. DiNallo}

The Pennsy/vania State University

jmd422@psu.edu

\begin{abstract}
To optimize public health in the next decade, prevention of childhood obesity will remain a central focus. To impact behavioral change, data must be linked to continuous quality improvements within existing nutrition and physical activity programming. The Children, Youth, and Families At-Risk Professional Development and Technical Assistance Center has developed a picture-based, online survey tool, the CYFAR Health Assessment Tool (CHAT), to assess health behaviors in youth ages 6 to 18 years of age. Used for continuous program improvement, aggregate data results are coupled with tailored health recommendations in 4 domains (behavior and environmental modifications, education, and direct strategies) and evidence-informed resources for dissemination to youth and parents. Program implementers use the data and resources for targeted programmatic improvements that more effectively promote health and well-being. CHAT also informs our collective understanding of youth's perceptions of health in comparison to their actual behaviors.
\end{abstract}

Key words: childhood obesity, youth, CYFAR, after-school, CHAT, nutrition, physical activity, health

(cc) EY New articles in this journal are licensed under a Creative Commons Attribution 4.0 License. This journal is published by the University Library System, University of Pittsburgh and is cosponsored by the University of Pittsburgh Press. The Journal of Youth Development is the official peer-reviewed publication of the National Association of Extension 4-H Agents and the National AfterSchool Association. 


\section{Introduction}

Prevalence of childhood obesity in the United States has risen dramatically over the last three decades (Han, Lawlor, \& Kimm, 2010). Since 1980, obesity rates for children have tripled, with rates of obese children ages 6 to 11 years doubling and rates of obese adolescents ages 12 to 19 years quadrupling (Segal, Rayburn, \& Beck, 2017). The 2015-2016 National Health and Nutrition Examination Survey administered by the Centers for Disease Control and Prevention indicates rates of obesity are higher among school-age youth of 6 to 11 years and adolescents (18.4\% and $20.6 \%$, respectively) compared with children ages 2 to 5 years (13.9\%) (Hales, Carroll, Fryar, \& Ogden, 2017).

Moreover, racial, ethnic, and economic disparities prevail. The 2017 State of Obesity: Better Policies for a Healthier America reported that the highest prevalence of obesity is among Latinos (21.9\%) and Blacks (19.5\%); Latino males had the highest percent at $22.4 \%$. American Indian/Alaska Native children also have high rates of obesity, with $31 \%$ of children ages 6 to 19 years identified as obese (Segal et al., 2017). The State of Obesity website highlights statistics drawn from the 2007 National Survey of Children's Health that indicate, nationally, children living in low-income neighborhoods are up to $60 \%$ more likely than other children to be overweight or obese (Trust for America's Health and Robert Wood Johnson Foundation, n.d.).

Social and economic disparities, reflected in reduced opportunities to make healthy choices where people live, learn, work, and play, contribute to obesity rates for vulnerable populations (Levi, Segal, Laurent, \& Rayburn, 2014). As examples, a U.S. Department of Agriculture (USDA) study found 29 million Americans lack access to a supermarket within a mile of their home in urban areas and 10 miles of their home in rural areas, making these individuals less likely to consume a healthful diet and maintain a healthful weight (Ver Ploeg et al., 2012). Zip codes with higher Black populations have about half the number of chain supermarkets compared with zip codes with predominantly White residents (Levi et al., 2014). A 2017 report on obesity in the United States asserts that many low-resource neighborhoods are food deserts whose small food outlets and fast food restaurants sell and advertise unhealthy food and beverages and lack fresh healthier choices at affordable prices (Segal, et al., 2017). Studies have also found fewer parks, sports fields, fitness clubs, and walking or biking trails in low-income neighborhoods, making residents less likely to engage in safe and free physical recreation easily (Estabrooks, Lee, \& Gyurcsik, 2004; Powell, Slater, \& Chaloupka, 2004; Sallis \& Glanz, 2006). Low-income neighborhoods have been found to be 4.5 times more likely than high-income neighborhoods to 
lack recreational facilities (e.g., pools, tracks, tennis courts, and sports fields) (Moore, Roux, Evenson, McGinn, \& Brines, 2008; Segal et al., 2017).

The complex nature of childhood obesity has made it difficult to design effective programming solutions. Social determinants of health are statistically significant predictors of youth's health perceptions, including gender of youth, family socioeconomic characteristics, parents' education level, household living conditions, and the number of household dependents (Masa \& Chowa, 2013). However, at present, no one program has effectively influenced the increasing rates of overweight youth and families, particularly in vulnerable populations.

A study examining youth in Georgia found young people commonly perceive obesity as a problem but have less understanding of the link to lifestyle choices or to future morbidities; this finding suggests a need for education emphasizing healthy lifestyle behaviors (Sylvetsky et al., 2013). Consequently, linking youth's perceived understanding of health with their actual behaviors through targeted, programmatic enhancements can influence the prevalence of childhood obesity.

\section{After-School Programs-A Promising Approach}

Community-based programs can play an integral role in encouraging physical activity and healthy dietary habits. A systematic review of childhood obesity prevention programs found environment is a contributor to obesity risk and that comprehensive approaches that include the community are necessary (Bleich, Segal, Wu, Wilson, \& Wang, 2013). Youth generally have little to no control over their environments, so community-based interventions that focus on both diet and exercise and engage schools are most effective (Bleich et al., 2013; McGuire, 2012).

A promising approach to improving the health and wellness of youth is targeting after-school programs for the delivery of education and outreach strategies. Mahoney, Lord, and Carryl (2005) reported participation in after-school programs is associated with positive health outcomes, including reduced obesity. From providing students nutritious foods during snack time, to providing education on healthy habits, to keeping students physically fit through planned active games and recreation activities, after-school programs can influence healthrelated behaviors (Afterschool Alliance, 2014). 
Health Assessment Tool: Youth Obesity Prevention

The USDA's National Institute of Food and Agriculture's (NIFA) Children, Youth and Families AtRisk (CYFAR) Program has supported quality, comprehensive community and after-school programming for at-risk children, youth, and families for 37 years. Project sites develop and deliver educational programs that equip limited-resource individuals who are at risk for not meeting basic human needs with the skills necessary to lead positive, productive, contributing lives. At any point in time, approximately 40 to 50 funded projects are implemented. All are community-based and many operate in after-school settings. These projects have been test sites for the development of an innovative health assessment tool that provides important feedback to help programs continuously improve in order to achieve targeted outcomes.

\section{CYFAR Health Assessment Tool (CHAT)}

To optimize public health, prevention of childhood obesity must remain a central focus of youth programming. To date, efforts have failed to make assessment results actionable because health behavior surveys do not link the data to recommendations or resources that can be used to enhance program quality. The CYFAR Professional Development and Technical Assistance Center (CYFAR PDTA Center), a joint initiative of the University of Minnesota and the Pennsylvania State University, has developed an innovative CYFAR Health Assessment Tool (CHAT) to assess health behaviors with the direct intent of enhancing health programming among vulnerable populations in diverse contexts.

CHAT is an online, picture-based tool through which youth ages 6 to 18 years submit survey responses on their perceptions of their healthy choices and their behaviors related to nutrition, physical activity, sweetened beverage and water intake, screen time usage, and bedtime. The tool can be administered at a single point or multiple points in time and CYFAR project staff can use the data to inform how their organization or processes can be responsive to the youth behavior change needs identified from the assessment results. The aim is to move projects towards greater impact (i.e., reduced rates of childhood obesity) by helping programs to identify how processes (i.e., the curriculum content delivered, the design of program activities, and the materials selected for dissemination) can be enhanced to improve the effectiveness of programming efforts more strategically. The tool helps program staff (a) understand the behavioral needs, (b) be more intentional in planning aligned program content, and (c) be more efficient in using program time to address the most pressing behavioral factors related to participants' health. 
CHAT is designed to be employed by community, after-school, and school-based projects to inform physical activity, nutrition education, and behavior modification strategies among youth and their families. Following a project's survey administration, a CHAT coordinator, who is a registered dietitian nutritionist, generates a program-specific data report. The report summarizes the majority response for each question as a number and percentage of survey participants and also provides an explanation of the content specific to the question (e.g., the popular vegetables or fruits consumed). Recommendations are also put forth for the most striking data results using the evidence-informed components recognized in the literature for obesity prevention (i.e., education, behavior modification, environmental modification, and direct strategies). A sample of summarized data from a CHAT report is presented in Table 1.

Table 1. Responses to Questions on Fruit and Vegetable Consumption at Breakfast from a Sample CHAT Report

\begin{tabular}{|l|l|l|}
\hline Survey question & Majority response & $\begin{array}{l}\text { Response rate } \\
\text { (Number of youth and } \\
\text { percentage of total youth who } \\
\text { selected the majority response.) }\end{array}$ \\
\hline $\begin{array}{l}\text { Q1a - Yesterday, did you eat } \\
\text { any VEGGIES at BREAKFAST? }\end{array}$ & $\begin{array}{l}\text { No Veggies. } \\
\text { (Of those selecting vegetables, } \\
\text { carrots and other vegetables } \\
\text { were the most popular choice.) }\end{array}$ & $\begin{array}{l}50 \text { youth } \\
(42 \%)\end{array}$ \\
\hline $\begin{array}{l}\text { Q1B - Yesterday, did you eat } \\
\text { any FRUITS at BREAKFAST? }\end{array}$ & $\begin{array}{l}\text { Bananas. } \\
\text { (Apple slices, orange slices, and } \\
\text { other fruits were additional } \\
\text { popular choices. 19\% or } 23 \\
\text { youth selected no fruits.) }\end{array}$ & $\begin{array}{l}\text { (25\%) } \\
\text { (25) youth }\end{array}$ \\
\hline
\end{tabular}

Note. For each question, the response option most frequently selected by the surveyed youth was identified. The total number of surveyed youth selecting this option was counted and calculated as a percentage of the total number of surveyed youth.

Accompanying the report are resources drawn from the literature and respected health promotion campaigns designed to improve families' and children's health, such as MaineHealth Let's Go! (https://mainehealth.org/lets-go), the Military Clearinghouse for Family Readiness at 
Health Assessment Tool: Youth Obesity Prevention

Penn State's 5210 (https://5210.psu.edu/), and the USDA's MyPlate

(https://www.choosemyplate.gov/). The selected resources are tailored to participant needs and are provided to ease program staff's enactment of the recommendations. For example, if an after-school project's data showed low fruit consumption, the 5210 handout titled "Healthy Kids' Snacks" might be shared to suggest healthy snack options the program instructors could choose from to increase youth participants' consumption (Clearinghouse for Military Family Readiness at Penn State, 2017).

The intent is for survey data to drive program enhancements and for the resources provided to be incorporated into youth program lessons, used for family education sessions, and distributed as take-home handouts, so parents can reinforce positive behavioral change in the home. The data can also be shared with community partners to motivate societal institutions to work collaboratively to address policies and practices that hinder healthy lifestyles. For example, data showing low rates of physical activity might be shared with local public health departments, school districts, or other stakeholders to promote more safe recreation opportunities such as walking and biking routes to schools.

\section{Methods}

\section{Tool Development}

MaineHealth Let's Go! and 5210 public education initiatives informed CHAT development. These campaigns encourage community-wide messaging to improve the health of families and children and use research and recommendations from agencies such as the American Academy of Pediatrics (https://www.aap.org), the U.S. Department of Health and Human Services (HHS) (https://www.hhs.gov/), and the National Association for Sport and Physical Education (https://www.shapeamerica.org) to urge children to commit to the following 5210 behaviors:

- Consume $\mathbf{5}$ or more servings of fruits and vegetables daily.

- Engage in $\mathbf{2}$ or fewer hours of recreational screen time daily.

- Be physically active for more than $\mathbf{1}$ hour daily.

- Consume $\mathbf{0}$ sweetened beverages.

In addition, a review of literature explored existing youth nutrition and physical activity questionnaires focused on 5210 behaviors. Very few were located that had published results, and the majority of those that were found were crafted to solicit the parent perspective (Anderson, Must, Curtin, \& Bandini, 2012; Bryant, et al., 2008; Gattshall, Shoup, Marshall, 
Crane, \& Estabrooks, 2008). Only one publication reviewed three school-based questionnaires and it assessed: (a) fruit/vegetable intake, (b) physical activity and television viewing, and (c) perceived parental support for diet and physical activity (Economos et al., 2008). The first two of these questionnaires were child-directed; the last one was aimed at parents. The childdirected questionnaires were used as guides in developing the CHAT nutrition and physical activity questions.

Validated survey questions to gauge electronic usage and bedtimes were sought. While parent proxy assessments of screen time exist, no validated measures of child-reported screen time use at bedtime were identified. During CHAT development, two survey questions regarding screen time use and bedtime were included.

\section{Current Design of CHAT}

CHAT is an online tool (Qualtrics, Version 1.0, 2018) that collects self-report data from youth ages 6 to 18 years. The questionnaire, composed of demographic and behavioral questions, uses sets of pictures to assist with recall of the prior day's health behaviors. CHAT questions include the following.

\section{Demographic Questions}

Five questions collect geographic location, age, gender, and race. The questions are asked using pictures and a sliding response bar.

\section{Question Assessing Perception of Healthy Choices}

Research indicates that youth understand obesity to be a problem, but they do not necessarily recognize the connection between obesity and lifestyle choices (Sylvetsky et al., 2013). Accordingly, one question assesses participants' perception of the frequency with which they make choices that help them live a healthy life.

\section{Nutrition Questions}

CHAT contains 10 nutrition-related questions. Research and national dietary guidelines emphasize the importance of healthy nutrition for youth. For example, the 2015-2020 Dietary Guidelines for Americans recommends adopting healthy eating patterns such as increasing fruit and vegetable intake, especially dark-green, red, and orange vegetables, to reduce the risks of 
cardiovascular disease, type 2 diabetes, cancer, and some neurocognitive disorders (HHS \& USDA, 2015). In addition, the Robert Wood Johnson Foundation Healthy Eating Research program concluded that reducing sweetened beverage consumption would not only decrease the risk of childhood obesity, but also impact rates of type 2 diabetes, poor nutrition, excess caffeine consumption, and dental decay in youth (Bleich \& Vercammen, 2018; Gortmaker, Long, \& Wang, 2009). This is reinforced in the 2015-2020 Dietary Guidelines for America which recommend choosing beverages with no sugars to help limit sugar consumption to less than $10 \%$ of one's daily calories (HHS \& USDA, 2015).

Pictures are attached to each nutrition-related question to ease youth's answer selections. Questions refer to the day before (yesterday). Youth are asked to recall fruits and vegetables consumed during breakfast, lunch, dinner, and after-school snack, and water and sweetened beverage consumption. The survey displays sets of pictures of popular food and beverage selections, plus the option of selecting "none," "other," or "I do not wish to answer," when indicating which fruits, vegetables, and beverages were consumed. A sample of a nutrition question is presented in Figure 1.

Figure 1. Sample CHAT Nutrition Question

Click all of the pictures of the FRUITS you ate YESTERDAY for BREAKFAST.
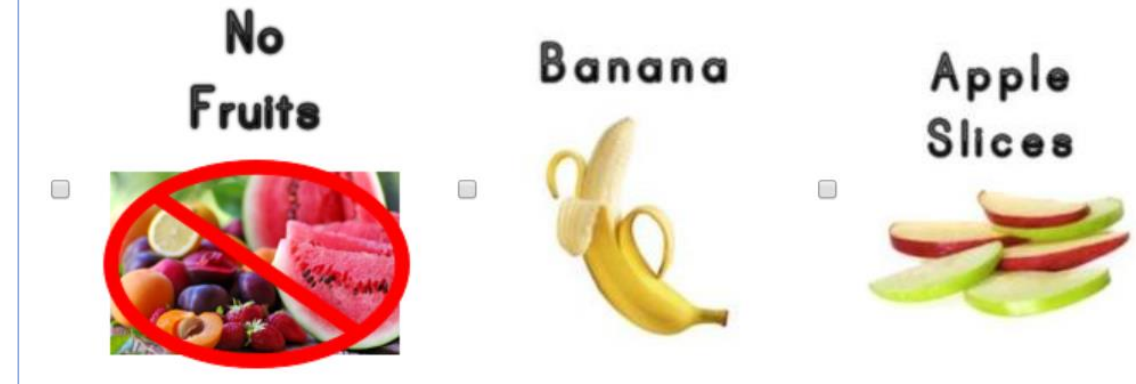

Orange Slices
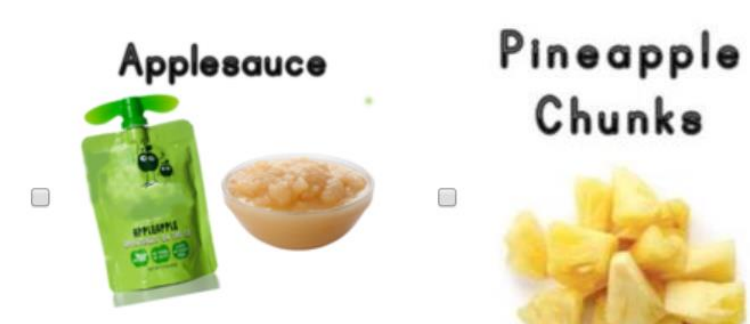

Fruit Cup
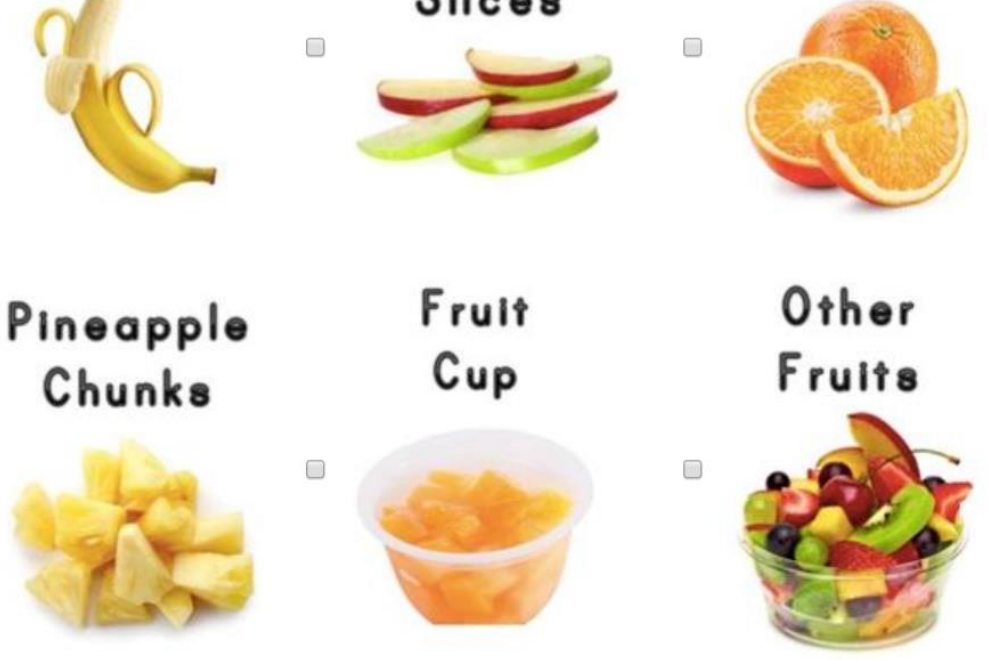


\section{Physical Activity Questions}

Three questions assess current behavior patterns related to daily active play, such as playing outdoors after school and at home, as well as the intensity of the physical activity. These questions are based on recommendations for children and adolescents that promote 60 minutes or more of physical activity daily and vigorous-intensity aerobic activity at least three days weekly (HHS, 2008). A sample of a CHAT physical activity question is presented in Figure 2.

\section{Figure 2. Sample CHAT Physical Activity Question}

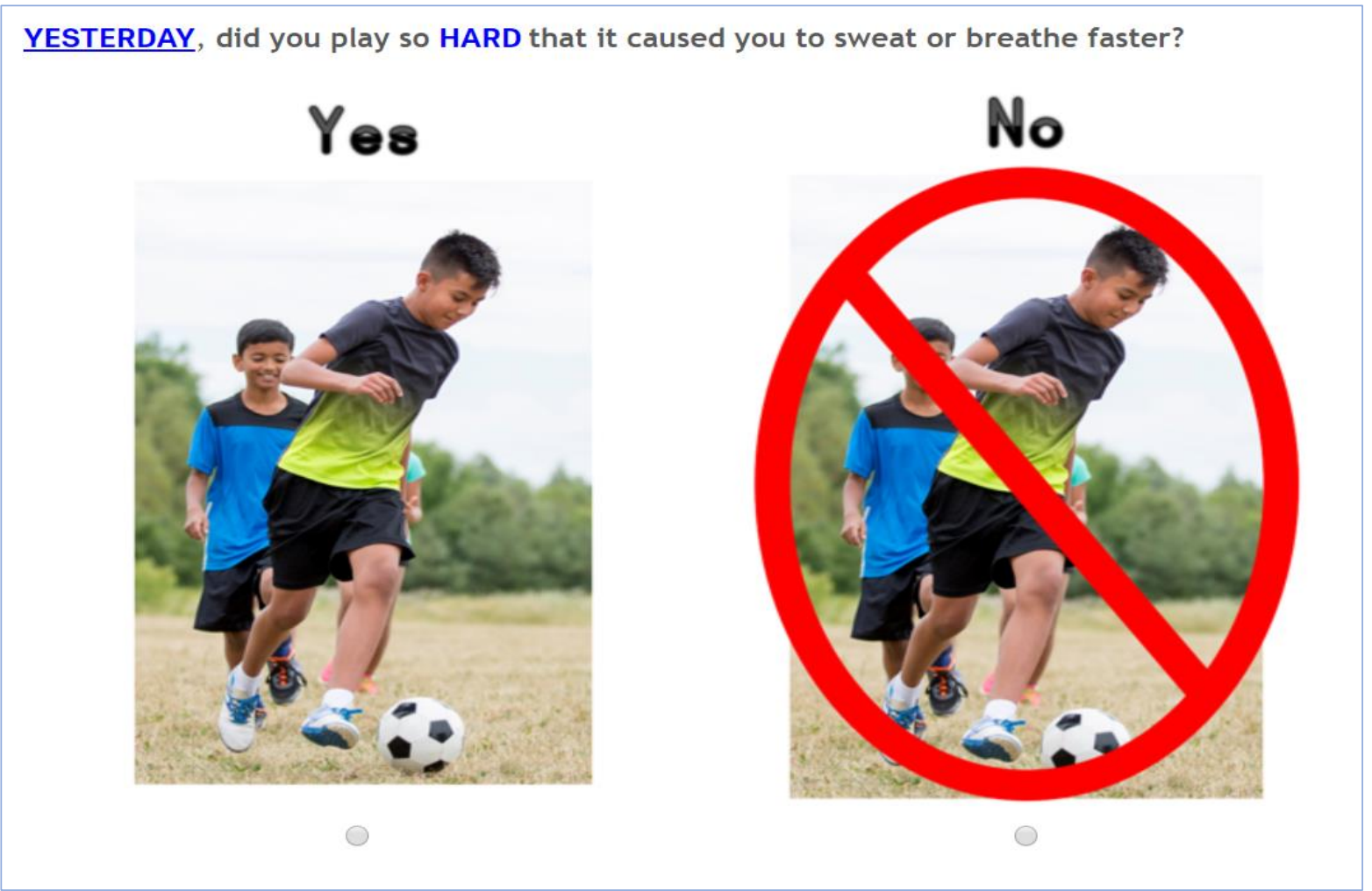

\section{Screen Time Questions}

Two questions assess when electronics, in a variety of formats (e.g., television, smart phone, and computer) are used and if electronics are used at bedtime. A strong link exists between bedtime use of electronic devices and poor sleep, inadequate sleep and excessive daytime sleepiness (Carter, Rees, Hale, Bhattacharjee, \& Paradkar, 2016). A study found children using mobile media devices at bedtime are more than twice as likely to sleep less than 9 hours a night. Those who kept phones or other gadgets in their rooms were likely to get poor sleep and be excessively sleepy during the day (Carter et al., 2016). 


\section{Bedtime Question}

A question about youth bedtimes completes the questionnaire. Sleep is an essential part of child development and is directly related to productive functioning at school (Vriend et al., 2013) and healthy weight status (Chaput, 2016). Many children and adolescents are not sleeping enough; the American Academy of Sleep Medicine and American Academy of Pediatrics recommend 9 to 12 hours of sleep per 24 hours for children ( 6 to 12 years) and 8 to 10 hours per 24 hours for adolescents (13 to 18 years) (Paruthi et al., 2016). Most adolescents (60\%) are sleeping less than eight hours each night (National Sleep Foundation, 2011). One contributing factor for reduced sleep quantity and quality is the use of electronics. A Sleep in America poll showed that $97 \%$ of adolescents have at least one screen in their bedroom (National Sleep Foundation, 2006). Two studies found that evening screen time of one or more hours was associated with a 3.4-fold increased risk in going to bed significantly later (i.e., 11 p.m. or later) (Foley et al., 2013; Kubiszewski, Fontaine, Rusch, \& Hazouard, 2014).

\section{Usability}

CHAT is easy to use for children ages 6 to 18 years. Although children are commonly viewed as unreliable informants, this premise has been traded against the benefits of directly questioning children who are being carefully guided during survey administration. Projects that register to use the CHAT tool are provided with a facilitator guide and survey administration instructions to mitigate potential validity concerns. Participants' comprehension of survey questions, recall, and understanding of the survey process is promoted in the following ways:

- Advantages identified in dietary assessments for children are built in, such as a short administration time, a defined recall time, low respondent burden, and reductions in literacy demands due to the use of pictures (McPherson, Hoelscher, Alexander, Scanlon, \& Serdula, 2000).

- Recall generally agrees more with validation standards than food frequency questionnaires; CHAT does not ask participants to recall food frequency or portion sizes (McPherson et al., 2000).

- Facilitators are encouraged to engage participants in a discussion prior to survey administration to explain the process and encourage accurate answering

- Facilitators are to be available to troubleshoot or answer questions as youth complete the survey.

- As the survey date is pre-established, on the day prior to the survey, facilitators can involve participants in writing down foods consumed, so the list can be referenced during survey administration. 


\section{Usability Testing}

During tool development and testing, CHAT provided self-reported health behaviors of youth enrolled in CYFAR community-based and after-school programs. Below is a description of how a beta-test and pilot study informed refinement of the tool.

\section{Beta Test Description}

A convenience sample of children was recruited through the Clearinghouse for Military Family Readiness at Penn State for initial usability testing. Then, CYFAR sites in three states were selected in July 2016 to participate in a beta test based on the age of participants and the structure of each site's youth programs.

The beta test targeted children 6 to 12 years of age enrolled in after-school, health-focused programs. Thirty-eight youth ( $M=9.2$ years; $S D=2.1)$ completed surveys, with at least three children in each age group from the three states (Pennsylvania, Oregon, and North Carolina). Data analysis and facilitator interviews were used to obtain feedback about the process of completing the survey including technology or survey completion barriers, perceived value of the tool, and perceptions of the tool's usability.

\section{Pilot Study Description}

Following beta testing, an effectiveness-implementation pilot study was conducted with CYFAR sites in four states and territories (Nebraska, Tennessee, Rhode Island, and the U.S. Virgin Islands) in October 2016. One facilitator was identified to administer the tool at the respective sites. Youth participants (ages 5 to 11 years) completed the online survey multiple times using a computer or tablet that contained the same self-report measures from the beta-test with minor wording and formatting enhancements.

Following survey completion, results were compiled for each site into usable data reports and evidence-informed recommendations for program enhancements tailored to the identified participant needs were prepared. Parental and youth education materials and direct program strategies were highlighted for sites to incorporate into program lessons, family education sessions, and as take-home handouts. 


\section{Results}

\section{Beta Test Usability Results}

The perceived value of the tool during the beta test was favorably reported among all participating sites due to the engagement of youth through the interactive, electronic interface. Usability feedback shaped revisions. Changes focused on simplifying the demographic questions and providing resources, scripts, and advice for survey administrators to promote accurate recall behaviors. A pre-survey was developed to collect contextual information from site facilitators to reduce the demographic information requested of youth and to enable more tailored site recommendations and resources.

\section{Pilot Study Usability Results}

The pilot sites reported high survey usability. Findings were combined with feedback from phone interviews with site implementation staff one week after survey completion. Feedback drove format changes designed to clarify questions, increase visual appeal, and enhance survey question transitions. Data analysis prompted development of a master survey that could collect data as an aggregate across sites and allow for separation of the data by site for tailored sitespecific data reports. A question about water consumption was added to assess youth hydration practices. Skip patterns were added to prevent youth from selecting fruit/vegetables while also reporting no consumption.

\section{Lessons Learned for Increasing Youth Engagement}

From development through refinement phases, focus was placed on youth engagement with the tool and increasing the validity of youth responses. Initial tool development involved a committee, with knowledge of youth development and programming, who were tasked with reviewing photographs for their appeal to young children. Pictures were intended to create a more game-like experience for the survey participants and were expected to increase engagement over traditional pen-pencil survey processes that no longer appeal to technologysavvy Generation Z, the first population to be raised in the era of smartphones and a dominant social media culture. Research with online gamers and within schools has demonstrated validity for online testing and increased engagement by youth in technology-supported learning environments (Godzicki, Godzicki, Krofel, \& Michaels, 2013; Wood, Griffiths, \& Eatough, 2004). Selected pictures were chosen as reflections of common foods, beverages, and electronics. 
When relevant, a picture marked with "other" was included to provide the option of indicating consumed fruits, vegetables, or sweetened beverages not pictured.

The inclusion of photographs into the survey was done innovatively and strategically to increase engagement and prompt better recall. Even for preschool children, research has shown that children as young as 4 years old remember personally-experienced events (Bauer et al., 2012) and that pictures are better retained than words (Corsini, Jacobus, \& Leonard, 1969). Visual approaches have been reported as appropriate for research with children and as effective elicitation techniques (O'Connell, 2013; Power, 2003). Research has also determined that incorporating visual elements into questionnaires leads to higher response quality, as participants who recognize a product in a picture seem to have a more direct association and are better able to give an opinion (Deutskens, de Ruyter, Wetzels, \& Oosterveld, 2004).

The most significant changes following the usability testing were:

- Demographic questions were simplified (e.g., slide bar added for youth to select their age and pictures added for gender identification).

- Some youth were confused by the terms "yesterday" and "after-school," so survey administrators are now directed to use the survey only during the school year and on Tuesdays through Fridays. Facilitators are also encouraged to define and discuss "yesterday" with the youth prior to survey completion.

- All items were changed to require youth to select at least one answer for each question, including the option of choosing "I do not wish to answer" because some questions were skipped by accident or on purpose.

- Transition statements were added to the survey and more photos were included. The intent of both is to help youth recall behaviors more easily at targeted time points (e.g., breakfast vs. lunch).

- Resources were developed (e.g., Ground Rules for Sites and Introducing the CHAT) including a script for site staff to read survey directions/questions aloud to any youth who struggle with reading or need more than the visual guidance.

\section{Aggregate Data Results}

In addition to assessing CHAT usability, pilot study data yielded site-specific and aggregate results. Aggregate data are presented below in Tables 2 through 7. Results reflect behaviors within 24 hours prior to survey completion. 
Journal of Youth Development | http://jyd.pitt.edu/ | Vol. 13 Issue 3 DOI 10.5195/jyd.2018.599 Health Assessment Tool: Youth Obesity Prevention

Table 2. Participant Demographics

\begin{tabular}{|c|c|c|c|c|c|}
\hline & Site 1 & Site 2 & Site 3 & Site 4 & Percentage \\
\hline \multicolumn{6}{|l|}{ Gender } \\
\hline - Girls & 5 & 10 & 17 & 18 & $62.5 \%$ \\
\hline - Boys & 6 & 7 & 10 & 7 & $37.5 \%$ \\
\hline Mean Age & 6.91 & 7.65 & 8.15 & 9.32 & \\
\hline \multicolumn{6}{|l|}{ Race } \\
\hline - White & 1 & 4 & 27 & 20 & $65 \%$ \\
\hline - Black & 9 & 4 & 0 & 5 & $22.5 \%$ \\
\hline - Asian & 0 & 3 & 0 & 1 & $.05 \%$ \\
\hline - Am IN/AK Native & 1 & 4 & 0 & 2 & $8.75 \%$ \\
\hline - Native Hawaiian & 0 & 3 & 0 & 1 & $.05 \%$ \\
\hline \multicolumn{6}{|l|}{ Ethnicity } \\
\hline - Hispanic & 4 & 14 & 27 & 5 & $62.5 \%$ \\
\hline - Non-Hispanic & 7 & 3 & 0 & 20 & $37.5 \%$ \\
\hline
\end{tabular}

Note. $N=80$. During the pilot, survey respondents could select more than one response for race/ethnicity. The options have since been modified to limit the choice to one response.

Table 3. Percentages for Youth's Consumption of Vegetables and Fruits

\begin{tabular}{|l|c|c|}
\hline Meal & Vegetables & Fruit \\
\hline Breakfast & $44 \%$ & $71 \%$ \\
Lunch & $74 \%$ & $82 \%$ \\
Dinner & $62 \%$ & $60 \%$ \\
After-school snack & $33 \%$ & $69 \%$ \\
\hline
\end{tabular}

Note. The totals for the four sites were summed and then averaged. The most commonly consumed fruits/vegetables were apple slices, banana, salad, corn, and carrots. 
Journal of Youth Development | http://jyd.pitt.edu/ | Vol. 13 Issue 3 DOI 10.5195/jyd.2018.599

Health Assessment Tool: Youth Obesity Prevention

Table 4. Percentages for Youth's Daily Active Play

\begin{tabular}{l|l} 
Reporting physical exertion & $70 \%$ \\
Active at after-school program & $92 \%$ \\
Active at home & $82 \%$ \\
\hline
\end{tabular}

Note. The totals for the four sites were summed and then averaged.

Table 5. Percentages for Youth's Consumption of Sweetened Beverages

\begin{tabular}{|l|l|}
\hline Range of consumption percentages & $56 \%-100 \%$ \\
Average percentage of consumption & $84 \%$ \\
\hline
\end{tabular}

Note. The total number of youth consuming sweetened beverages at each of the four sites was calculated as a percentage. The range of percentages for the four sites is presented, as well as the average percentage of the four sites. The most commonly consumed sweetened beverages were soda and drink pouches.

\section{Table 6. Percentages for Youth's Daily Electronics Usage}

\begin{tabular}{|l|l}
\hline Range of percentages for daily usage & $40 \%-65 \%$ \\
Average percentage of daily usage & $56 \%$
\end{tabular}

Note. Youth at the four sites were asked to select all the times they watched television or videos and played video or computer games. The total number of youth selecting any times at each of the four sites was calculated as a percentage. The range of percentages for the four sites is presented, as well as the average percentage of the four sites.

\section{Table 7. Times Youth Most Frequently Cited for Electronics Usage}

\begin{tabular}{|l|l|l|}
\hline & Range of reported usage & Average usage \\
\hline After-school & $55 \%-77 \%$ & $62 \%$ \\
\hline Bedtime & $40 \%-67 \%$ & $56 \%$ \\
\hline
\end{tabular}

Note. Youth at the four sites were asked to select all the times (i.e., morning, lunch, after school, evening, in bed) they watched television or videos and played video or computer games. The top two times for each site were identified as a percentage. The percentages of the four sites were averaged. 
Health Assessment Tool: Youth Obesity Prevention

Table 8. Times Youth Cited for Bedtimes

\begin{tabular}{l|l} 
Range of youth bedtimes & 7 p.m. - 11+ p.m. \\
Most common bedtime & 8 p.m. \\
Percentage reporting most common bedtime & $39 \%$
\end{tabular}

Note. Participants are asked to report their usual bedtime on school nights. $8.72 \%$ of the surveyed youth reported not having a bedtime. Youth selected all the response options (7 p.m. to 11 p.m. or later). The most commonly selected bedtime was 8 p.m., followed by 9 p.m.

\section{Discussion}

\section{Limitations}

CHAT is currently not without limitations, and continues to be refined. Community-based and after-school programs, particularly in rural locations may lack or have limited access to electronic devices and/or unreliable Internet connections. Because the tool is only available as an electronic survey, some sites may be unable to administer it, especially in large group settings. Another limitation is that youth may struggle to recall behaviors from "yesterday." Although facilitation strategies are provided to encourage accurate and complete recall, a research study suggests that 24-hour diet recall in children results in low reliability due to both variations in diet across days and inaccuracy in reporting (George, Van Horn, Lawman, \& Wilson, 2016). Next, the current survey format does not include audio instructions. Although the picture-based format increases engagement and readability, literacy issues can still prevent accurate reporting. Lastly, a future study will be necessary to assess the impact of CHAT recommendations and reports upon actual programmatic improvements and behavioral changes in the targeted youth. The ability exists within the data system to analyze the participant responses by gender, age, race, and geographic location. Additional tools and processes will be needed to gather information from survey administrators, youth, and families to assess changes across time in programming and behaviors.

Despite limitations, CHAT actively engages youth in identifying health behaviors using a picturebased design that focuses on targeted programmatic improvements. As educators strive to promote health and well-being across various youth ecologies, efforts will be strengthened by actionable data sets that can be linked to continuous quality improvements within their existing nutrition and physical activity programming. The provision of data and evidence-informed 
resources is intended to disburden program staff and boost their use of effective strategies for health promotion with youth and parents.

\section{Programmatic and Policy Implications}

\section{Programmatic Improvements}

The data from intentionally surveying youth about how they perceive their nutrition, fitness, screen time, and bedtime habits, is used to customize reports that the program sites can use for targeted programmatic improvements. Recommendations for education, behavior modification, environmental modification, and direct strategies are also provided to match identified needs. The recommendations and resources are based in the obesity prevention and intervention literature and are designed to influence how programs (a) tailor meal or snack offerings, (b) incorporate physical activities into programming, (c) provide education, and (d) disseminate resources to youth and their parents.

\section{Youth and Family Health and Lifestyle Choices}

Health-enhancing behaviors (e.g., nutrition and physical activity) are shaped and adopted in childhood and persist into adulthood (Raj, Senjam, \& Singh, 2013). Empowered with data that create an understanding of how youth eat, move, and spend their time inside and outside of programs, community-based and after-school organizations can assume a role in supporting children's health and quality of life. CHAT has the potential to influence behavioral domains in the home by equipping programs with resources that offer guidance and creative strategies (e.g., healthy recipes or family-centered physical activities) for parents to tackle the targeted CHAT behaviors. Engaging families can play a key role in reinforcing the health lessons taught to youth in community-based and after-school programs as parents can be encouraged to enact strategies such as providing nutritious family meals, reducing the availability of sweetened beverages, and modeling physical activity (Lindsay, Sussner, Kim, \& Gortmaker, 2006).

\section{Community Funds and Policies}

CHAT data reports can be shared with community partners to impact local policies and funding dollars. For example, data showing low fruit or vegetable consumption at breakfast and lunch could be used to motivate school administrators to increase the amount of local, fresh, highquality produce served in the school cafeteria or to influence local health departments or community stakeholders to provide in-kind resources to support nutrition education or the establishment of school gardens. Using data to improve school meals is important as children 
and adolescents can consume up to half of their total daily calories at school (Briefel, Wilson, \& Gleason, 2009; Gleason \& Suitor, 2001).

\section{Future National Implications}

Future modifications to CHAT and testing can be used to assess positive behavioral change. For example, how are programs doing at using the recommendations provided? Do the results provide insight into national geographical differences across the behavioral domains? With questions in mind, a larger-scale study can examine the effectiveness of actionable data sets and enhanced health programming on youth in community-based, after-school settings.

In the long-term, CHAT can be a mechanism through which youth across the nation inform our understanding of their perceptions of health in comparison to actual behaviors. As aggregate evidence is collected, existing youth development programs will be led to enact data-driven programmatic improvements and communicate data results locally to strengthen platforms for policy change and to solicit funding for health improvement efforts. Ultimately, data-driven, continuous quality improvement of programming can impact community environments and the American health landscape.

\section{Acknowledgements}

The authors acknowledge Frank Materia, MHS; Jonathan Olson, Ph.D.; and Jennifer WellsMarshall, Ph.D. for their contributions to the development and testing of CHAT.

This work was supported by the U.S. Department of Agriculture's National Institute of Food and Agriculture (USDA-NIFA) through a cooperative agreement with the University of Minnesota and the Pennsylvania State University under award number 2013-41520-21529.

\section{References}

Afterschool Alliance. (2014). America after 3PM: Afterschool programs in demand. Retrieved from http://afterschoolalliance.org/documents/AA3PM-2014/AA3PM_National_Report.pdf

Anderson, S. E., Must, A., Curtin, C., \& Bandini, L. G. (2012). Meals in our household: Reliability and initial validation of a questionnaire to assess child mealtime behaviors and family mealtime environments. Journal of the Academy of Nutrition and Dietetics, 112(2), 276-284. doi: 10.1016/j.jada.2011.08.035 
Bauer, P. J., Doydum, A. O., Pathman, T., Larkina, M., Güler, O. E., \& Burch, M. (2012). It's all about location, location, location: Children's memory for the "where" of personally experienced events. Journal of Experimental Child Psychology, 113(4), 510-522.

Bleich, S. N., Segal, J., Wu, Y., Wilson, R., \& Wang, Y. (2013). Systematic review of community-based childhood obesity prevention studies. Pediatrics, 132(1), 201-210. doi: 10.1542/peds.2013-0886

Bleich, S. N. \& Vercammen, K. A. (2018). The negative impact of sugar-sweetened beverages on children's health: An update of the literature. BMC Obesity, 5(1), 6.

Briefel, R. R., Wilson, A., \& Gleason, P. M. (2009). Consumption of low-nutrient, energy-dense foods and beverages at school, home, and other locations among school lunch participants and nonparticipants. Journal of the American Dietetic Association, 109(2), S79-S90.

Bryant, M. J., Ward, D. S., Hales, D., Vaughn, A., Tabak, R. G., \& Stevens, J. (2008). Reliability and validity of the healthy home survey: A tool to measure factors within homes hypothesized to relate to overweight in children. International Journal of Behavioral Nutrition and Physical Activity, 5(1), 23.

Carter, B., Rees, P., Hale, L., Bhattacharjee, D., \& Paradkar, M. S. (2016). Association between portable screen-based media device access or use and sleep outcomes: A systematic review and metaanalysis. JAMA Pediatrics, 170(12), 1202-1208. doi: 10.1001/jamapediatrics.2016.2341

Chaput, J. P. (2016). Is sleep deprivation a contributor to obesity in children? Eating and Weight Disorders - Studies on Anorexia, Bulimia and Obesity, 21(1), 5-11. doi: 10.1007/s40519-0150233-9

Clearinghouse for Military Family Readiness at Penn State. (2017). Healthy kids'snacks. [Fact Sheet]. Retrieved from http://psu5210.wpengine.com/wpcontent/uploads/2017/08/b2_8healthykidssnacks7-11-17.pdf

Corsini, D. A., Jacobus, K. A., \& Leonard, S. D. (1969). Recognition memory of preschool children for pictures and words. Psychonomic Science, 16(4), 192-193.

Deutskens, E., de Ruyter, K., Wetzels, M., \& Oosterveld, P. (2004). Response rate and response quality of internet-based surveys: An experimental study. Marketing Letters, 15(1), 21-36.

Economos, C. D., Sacheck, J. M., Chui, K. K. H., Irizzary, L., Guillemont, J., Collins, J. J., \& Hyatt, R. R. (2008). School-based behavioral assessment tools are reliable and valid for measurement of fruit and vegetable intake, physical activity, and television viewing in young children. Journal of the American Dietetic Association, 108(4), 695-701. doi: 10.1016/j.jada.2008.01.001

Estabrooks, P. A., Lee, R. E., \& Gyurcsik, N. C. (2004). Resources for physical activity participation: Does availability and accessibility differ by neighborhood socioeconomic status? Annals of Behavioral Medicine, 25(2), 100-104.

Foley, L. S., Maddison, R., Jiang, Y., Marsh, S., Olds, T., \& Ridley, K. (2013). Pre-sleep activities and time of sleep onset in children. Pediatrics, 131(2), 276-282. 
Gattshall, M. L., Shoup, J. A., Marshall, J. A., Crane, L. A., \& Estabrooks, P. A. (2008). Validation of a survey instrument to assess home environments for physical activity and healthy eating in overweight children. International Journal of Behavioral Nutrition and Physical Activity, 5(1), 3. doi: 10.1186/1479-5868-5-3

George, S. M. S., Van Horn, M. L., Lawman, H. G., \& Wilson, D. K. (2016). Reliability of 24-hour dietary recalls as a measure of diet in African-American youth. Journal of the Academy of Nutrition and Dietetics, 116(10), 1551-1559. doi: 10.1016/j.jand.2016.05.011

Gleason, P., \& Suitor, C. (2001). Food for thought: Children's diets in the 1990s. (Policy Brief). Princeton, $\mathrm{NJ}$ : Mathematica Policy Research, Inc.

Godzicki, L., Godzicki, N., Krofel, M., \& Michaels, R. (2013). Increasing motivation and engagement in elementary and middle school students through technology-supported learning environments. Online Submission.

Gortmaker, S., Long, M., \& Wang, Y. C. (2009). The negative impact of sugar-sweetened beverages on children's health: a research synthesis. Robert Wood Johnson Foundation. Retrieved from http://healthyeatingresearch.org/wp-content/uploads/2013/12/HER-SSB-Synthesis091116_FINAL.pdf

Hales, C. M., Carroll, M. D., Fryar, C. D., \& Ogden, C. L. (2017). NCHS data brief: Prevalence of obesity among adults and youth: United States, 2015-2016 (No. 288). 1-8. Hyattsville, MD: National Center for Health Statistics.

Han, J. C., Lawlor, D. A., \& Kimm, S. Y. (2010). Childhood obesity. The Lancet, 375(9727), 1737-1748. doi: $10.1016 / \mathrm{S} 0140-6736(10) 60171-7$

Kubiszewski, V., Fontaine, R., Rusch, E., \& Hazouard, E. (2014). Association between electronic media use and sleep habits: An eight-day follow-up study. International Journal of Adolescence and Youth, 19(3), 395-407. doi: 10.1080/02673843.2012.751039

Levi, J., Segal, L. M., Laurent, R., \& Rayburn, J., (2014). The state of obesity: Better policies for a healthier America (Issue Report). Retrieved from the Trust for America's Health and Robert Wood Johnson Foundation State of Obesity website: https://stateofobesity.org/files/stateofobesity2014.pdf

Lindsay, A. C., Sussner, K. M., Kim, J., \& Gortmaker, S. (2006). The role of parents in preventing childhood obesity. The Future of Children, 169-186.

Mahoney, J. L., Lord, H., \& Carryl, E. (2005). Afterschool program participation and the development of child obesity and peer acceptance. Applied Developmental Science, 9(4), 202-215.

Masa, R., \& Chowa, G. (2013, November). Social and economic determinants of youth health perception: Evidence from the Ghana YouthSave experiment. Paper presented at the $141^{\text {st }}$ APHA Annual Meeting and Exposition, Boston, MA. Available at 
Health Assessment Tool: Youth Obesity Prevention

https://www.researchgate.net/publication/266813246_Social_and_economic_determinants_of_yo uth_health_perception_Evidence_from_the_Ghana_youthsave_experiment

McGuire, S. (2012). Institute of Medicine. 2012. Accelerating progress in obesity prevention: Solving the weight of the nation. Washington, DC: The National Academies Press. Advances in Nutrition: An International Review Journal, 3(5), 708-709. doi: 10.3945/an.112.002733

McPherson, S. R., Hoelscher, D. M., Alexander, M., Scanlon, K. S., \& Serdula, M. K., (2000). Dietary assessment methods among school-aged children: Validity and reliability. Preventive Medicine. 31, 11-33. doi: 10.1006/pmed.2000.0631

Moore, L. V., Roux, A. V. D., Evenson, K. R., McGinn, A. P., \& Brines, S. J. (2008). Availability of recreational resources in minority and low socioeconomic status areas. American Journal of Preventive Medicine, 34(1), 16-22.

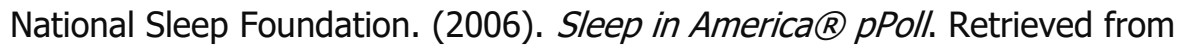
https://sleepfoundation.org/sites/default/files/Highlights_facts_06.pdf

National Sleep Foundation. (2011). Sleep in Americaß poll. Retrieved from https://sleepfoundation.org/sites/default/files/sleepinamericapoll/SIAP_2011_Summary_of_Findin gs.pdf

O'Connell, R. (2013). The use of visual methods with children in a mixed methods study of family food practices. International Journal of Social Research Methodology, 16(1), 31-46. doi: $10.1080 / 13645579.2011 .647517$

Paruthi, S., Brooks, L. J., D'Ambrosio, C., Hall, W. A., Kotagal, S., Lloyd, R. M., . . Rosen, C. L. (2016). Recommended amount of sleep for pediatric populations: A consensus statement of the American Academy of Sleep Medicine. Journal of Clinical Sleep Medicine, 12(6), 785. doi: 10.5664/jcsm. 5866

Powell, L. M., Slater, S., \& Chaloupka, F. J. (2004). The relationship between community physical activity settings and race, ethnicity, and socioeconomic status. Evidence-Based Preventive Medicine, 1(2), 135-144.

Power, E. M. (2003). De-centering the text: Exploring the potential for visual methods in the sociology of food. Journal for the Study of Food and Society, 6(2), 9-20.

Raj, S., Senjam, S. S., \& Singh, A. (2013). Assessment of health-promoting behavior and lifestyle of adolescents of a North Indian city. International Journal of Preventive Medicine, 4(10), 1189.

Sallis, J. F., \& Glanz, K. (2006). The role of built environments in physical activity, eating, and obesity in childhood. The Future of Children 16(1), 89-108.

Segal, L. M., Rayburn, J., \& Beck, S. E. (2017). The state of obesity: Better policies for a healthier America (Issue Report). Retrieved from the Trust for America's Health and Robert Wood Johnson Foundation State of Obesity website: https://stateofobesity.org/files/stateofobesity2017.pdf 
Sylvetsky, A. C., Hennink, M., Comeau, D., Welsh, J. A., Hardy, T., Matzigkeit, L., . . Vos, M. B. (2013). Youth understanding of healthy eating and obesity: A focus group study. Journal of Obesity, 2013, Article ID 670295. doi: 10.1155/2013/670295

Trust for America's Health and Robert Wood Johnson Foundation. (n.d.). Socioeconomics and Obesity among Children. Retrieved from https://stateofobesity.org/socioeconomics-obesity/

U.S. Department of Health and Human Services. (2008). 2008 physical activity guidelines for Americans: Be active, healthy, and happy!. Retrieved from https://health.gov/paguidelines/pdf/paguide.pdf

U.S. Department of Health and Human Services and U.S. Department of Agriculture. (2015). 2015-2016 Dietary Guidelines for Americans $8^{\text {th }}$ Edition. Retrieved from https://health.gov/dietaryguidelines/2015/resources/2015-2020_Dietary_Guidelines.pdf

Ver Ploeg, M., Breneman, V., Dutko, P., Williams, R., Snyder, S., Dicken, C., \& Kaufman, P. (2012). Access to affordable and nutritious food: Updated estimates of distance to supermarkets using 2010 data. (Economic Research Report 143). Retrieved from the U.S. Department of Agriculture, Economic Research Service website https://www.ers.usda.gov/publications/pubdetails/?pubid $=45035$

Vriend, J. L., Davidson, F. D., Corkum, P. V., Rusak, B., Chambers, C. T., \& McLaughlin, E. N. (2013). Manipulating sleep duration alters emotional functioning and cognitive performance in children. Journal of Pediatric Psychology, 38(10), 1058-1069.

Wood, R. T., Griffiths, M. D., \& Eatough, V. (2004). Online data collection from video game players: Methodological issues. CyberPsychology \& Behavior, 75$),$ 511-518. 